\title{
Digitization and the Reorganization of GVCs
}

\author{
Dev Nathan ${ }^{1}$
}

Published online: 23 September 2020

(c) Indian Society of Labour Economics 2020

Digitization has already been occurring, but it has been enormously accelerated in the period of the pandemic. As Satya Nadella, the CEO of Microsoft, put it, "We have seen 2 years of digital transformation in 2 months" (Bradley et al. 2020, 3). Some features of digitization have been the growth of telemedicine, online education, video conferencing instead of meetings, remote working and e-commerce, and automated manufacturing. We look at the last three trends mentioned, which are more important from the perspective of reorganization of value chains.

\section{Automation and On-Shoring}

Transport stoppages and the disruption of input supplies due to rolling lockdowns have intensified the move toward on-shoring, near-shoring, and the building of regional supply chains. Digitization, in the form of automated manufacturing, has begun even in labor-intensive industries such as garments and shoes (the quintessential commodities that involve outsourced manufacturing), low labor and environmental costs. Adidas has set up an automated shoe manufacturing factory in Germany, combining robots, 3-D printing, and digitization. Barely, 150 employees are required to produce half a million pairs of shoes per year. A T-shirt manufacturing plant, using Sewbots instead of tailors, has been set up in North Carolina, USA. There, the cost of production of a T-shirt is just 33 US cents, which is lower than the unit cost of manufacture in low-wage Bangladesh. A few years ago, an Indian auto-component manufacturer lost its orders for radiator caps for GM automobiles not to a lower-wage country but to high-wage Austria, where the production process had been automated. Low-wage labor-intensive manufacturing generally cannot compete with digitized and automated manufacturers. But the costs of reorganizing value chains, including investment in new, automated factories,

Thanks to Gerry Rodgers and Ed Steinmuller for comments. The author is with the Institute for Human Development, Society for Labour and Development and the GenDev Centre for Research and Innovation.

Dev Nathan

nathandev@hotmail.com

1 Institute for Human Development, Delhi, India 
would restrict the speed at which labor-intensive GVCs (global value chain) mention full form are reorganized.

In order to stay competitive in what have so far been labor-intensive value chains, China is also pushing strongly to deploy Sewbots and other automated technologies. On an annual basis, more robots are being installed in China than in any other country. Such automation, however, does not mean that the splintering of production on a global basis will cease to exist; rather, the erstwhile supplier countries and firms will also have to technologically upgrade if they are to stay within the value chains.

\section{India and GVCs}

The Indian economy has not been effective in using GVCs in the manner that China did, or as Vietnam is doing now. India has not benefited from some brands shifting labor-intensive production segments out of China because of increasing labor costs. Instead, these brands have moved to Vietnam and Bangladesh. The movement of GVC segments into India (like mobile phone assembly) has primarily been due to the fact that India is a large consumer market, helped by correction of an inverted tariff structure (higher for components than final products).

The idea seems to be that making labor cheap with no rights will attract GVC orders. Thus, various state governments have been competing to reduce or even abandon the protection of labor rights. This is a mistaken notion. For attracting GVC orders, what is important is unit production cost, not just wages. To attract relocation from China for GVC, orders will require skilled labor with the security of tenure in efficiently organized production units, along with good logistics and stable policy. China's experience highlights the importance of good infrastructure in being a reliable supplier. Further, in the last few years, Indian policy has been anything but stable_-right from the shock of demonetization to the botched GST rollout, as well as the disastrous lockdown without any social security. All these frequent policy shocks, with poor infrastructure and the perils of negotiating a powerful bureaucracy, have made India unattractive for GVC shifts.

Garment brands' actions during the pandemic, such as the cancellation of orders and demands for discounts, revealed in the Apparel Export Promotion Corporation's (AEPC) survey of suppliers (2020), have ruined the revenues of garment and leather export units. Large garment export factories with cash reserves are also taking steps to increase productivity and reduce employment. The fight to stay in the market during the recession will only intensify the push for higher productivity, which will result in a reduction in the employment intensity of production in manufacturing. Overall, whether in IT or other services or manufacturing, there is a continued push to increase productivity, causing a reduction in the employment intensity of output. 


\section{Regional Supply Chains}

There is also a trend of building regional supply chains (The Economist 2020). Much of it is due to the growth of substantial regional markets. Regionalization, however, is not just the result of the pandemic-induced disruption, but it heightens the importance of geopolitics in the world economy. Not just the USA, but also India, have taken steps to reduce their reliance on supplies of Chinese inputs and technology (for example, keeping Huawei out of $5 \mathrm{G}$ networks), overcoming the economic factors of cheapness in competitive production. But there is a limit to such nationalistic steps if a country is not price itself out of the international market.

Besides this, the regionalization of GVCs is something promoted by lead firms/ brands and their key (Tier-1) suppliers. China has developed numerous lead firms such as Huawei and ZTE for telecom equipment, Xiaomi and Oppo for mobile phones, Lenovo for computers, and Haier for household appliances. All of them promote their own value chains. India has very few such lead firms-Tata, Mahindra, Bajaj, and Hero, all in the automotive sector. These Indian lead firms have promoted their own value chains. Overall, however, India lags much behind China in building its own GVCs.

\section{Work from Home}

The trend of remote working, or "work from home," has become all-pervasive in India's IT services. The lockdowns and then the need to reduce numbers working in close proximity have promoted working from home. Indian IT majors such as TCS and Infosys have announced that they will continue with around 75 percent of their employees working from home even after post-pandemic normalcy. This will then lead to smaller office spaces, putting an end to the large campuses that have come to represent IT companies. But, companies will have to balance the cheapness of increased working from home and the benefits of co-working.

Working from home is also likely to have a positive impact on women's chances of promotion in the IT sector. It might not be necessary for them to take up transfers in order to be promoted. Remote working could not just be from the same city, but from another city or even another country. This is a possibility, and it remains to be seen how this will play out.

Work from home will require new forms of labor control. However, one should note that there are already forms of digital supervision of labor that have been called "digital Taylorism" (see Noronha and D'Cruz 2016). These will now be generalized to being remote supervision. 


\section{Growth in E-Commerce}

The largest transformation is the growth of e-commerce, which grew (on a global scale) by the same amount in 8 weeks during April-May 2020, as it had over the entire previous decade (Bradley et al. 2020, 3). Lockdowns led to a huge increase in the home delivery of essentials. With the threat of intermittent lockdowns, this trend is not likely to be reversed and the "new normal" will have greater reliance on e-commerce and home delivery.

As one would expect, the growth of e-commerce has mostly benefited hypersized enterprises such as Amazon or Alibaba. Global consumer e-commerce was 14.1 percent of global retail sales (Steenkamp 2020, 14). Alibaba now accounts for one-sixth of retail sales in China. In a Singles' Day mega sale, Alibaba carried out 250 million transactions in a single day. Amazon is now the largest retailer of almost every major retail item, including fashion garments. These are unprecedented levels of concentration. In addition, these giants of e-commerce (such as Amazon) are also oligopolies in other sectors too, such as cloud services, where Amazon is fighting with Microsoft and Google for market dominance.

\section{Hyper-Enterprises}

From having had oligopolies in single-product markets, we now have oligopolies that exist in several markets simultaneously. It is these hyper-enterprises' ability to link data across discrete sectors that enables them to establish these simultaneous oligopoly positions, along with their hyper-scale. Hyper-enterprises may be briefly defined as those with scales in hundreds of millions of customers or subscribers, and oligopoly positions in more than one market.

A good example of how hyper-enterprises function is the emerging Indian hyper-enterprise Reliance. The Reliance Jio telecom network has a subscriber base of 400 million subscribers. With the use of Facebook's WhatsApp and the to-be-established 5G network, with Google-Android support, data from retail stores linked to Reliance Retail can be combined with data from telecom. Such combining of data from across sectors is important for machine learning or artificial intelligence (AI) systems. The quality of AI systems depends on the quantity of data they can be provided. Hyper-volumes build a competitive advantage and make it very difficult for newcomers to enter the market. As Eric Schmidt, a former CEO of Google, put it, "Managing search at our scale is a very serious barrier to entry" (quoted in Zuboff 2019, 88).

Platforms with hyper-volumes operating across sectors are able to link their data from one sector with data from another. This is a novel form of interaction or synergy, which is used to improve behavioral prediction, leading to the creation of targeted advertising. This targeted advertising is made possible by platforms carrying out continuous surveillance of online behavior. Have you ever wondered why, as soon as you begin to look for flights to Kathmandu on a travel platform, 
advertisements for hotels in Kathmandu pop up on your computer screen? This is because the travel platform, such as MakeMyTrip or Expedia, uses your travel information to sell or utilize targeted advertising. This makes advertising much more likely to be successful instead of the usual scattershot method of advertising on television and other media.

In addition to scale and linkage across data sets, there is a concentrated knowledge effect (Foster and McChesney 2014). GVCs are based on the knowledge that lead firms are able to utilize though Intellectual Property Rights (IPR) protection, building market power in the product market; however, producing firms do not have similar IPR-protected market power (Nathan 2020). IPR-protected knowledge may include technology patents, trademarks, designs, and related reputational assets. The hyper-scale platforms carry forward their concentrated knowledge through "network effects, technical standards, patent law, and good-old fashioned barriers to entry to lock in their market power" (Foster and McChesney 2014, 19).

\section{Surveillance Capitalism}

The utilization of the behavioral data of individuals, collated across multiple domains and transactions, has been named "surveillance capitalism" by Shoshana Zuboff (2019). Capitalism has always had some manner of surveillance, whether through checking television viewership or consumer behavior through Point-of-Sale (POS) systems. However, it is the linking of actions across multiple domains and the continuity of that surveillance (from womb to tomb, as it has been called) that makes it possible to identify an age of surveillance capitalism as distinct from the age of mass production.

Production is still either mass- or small-batch production. However, is it driven by the hyper-scale business of e-commerce and related platforms? That is the key question posed by this note.

\section{Hyper-Enterprises and Bargaining Power}

The EU's note on Platform to Business Regulation (EU 2019/1150) states, "Traditional businesses are increasingly dependent on a limited number of large online platforms. This leads to imbalances in the bargaining power between large online platforms on the one hand and their users and rivals on the other, a trend which is expected to increase in the future," (EU 2020).

Some effects of platforms, even though they do not belong to the hyper-category, in reorganizing existing value chains can already be noticed in India. Food delivery aggregators are reorganizing restaurant value chains. Before the pandemic, food delivery sales had reached 25-30 percent of restaurant sales. With the restrictions on in-restaurant dining, the proportion of sales due to take-outs will certainly have more than doubled. Will this trend continue in a situation where there are no restrictions on in-restaurant dining? If the primary motivation for restaurant dining is to 
savor different kinds of cooking, then it is likely that this will become the new normal, just as ordering books online has become the new normal.

What about bargaining power between producers (restaurants, publishers, garment manufacturers) and platforms? The producers clearly fall into the category of lead firms who run their value chains, setting prices and influencing margins all along the chain. However, their growing dependence on aggregator platforms seems to have led to changes in bargaining power. For instance, while competing for market share, aggregators have forced restaurants to offer discounts. This started before the pandemic. Some of the better-known restaurants, with brand recognition, left the aggregators. Now, with the greater dependence of restaurants on aggregators, it is unlikely that even well-known restaurants will be able to make such threats. Chains that provide large volumes of business may, however, have some more bargaining power because of the volume of the business they could provide, compared to standalone restaurants.

Major international garment and luxury brands, who also have their own online sales programs, are likely to have greater bargaining power than smaller or new brands that rely almost entirely on the platforms for their online sales. However, even with large brands, one should note that there is a compulsion to be online with the platforms, since the number of visitors is likely to be higher than with ownbrand websites (Steenkamp 2020, 16).

\section{Conclusion}

Through the pandemic-induced recession, the importance of hyper-platformbased e-commerce will increase in the global economy and in India, as has already occurred in China. In which case are we going to see the creation of some "superbrands" or "hyper-brands," which may constrain the terms on which what we now call lead firms or brands function? Will what are now lead firms become "own equipment manufacturers," rather than brands? Will economic rents move from manufacturers to the hyper-platforms? Will these hyper-brands also become the setters of new international labor, gender, and environmental standards? So far, they have not ventured into such territory. However, this could change if enough consumer and reputational pressure is brought on them, which could happen through campaigns going viral to reach hyper-scale.

\section{References}

Apparel Export Promotion Corporation (AEPC). 2020. Impact of COVID on Indian Apparel Exports. www.aepc.com.

Bradley, Chris, Martin Hirt, Sara Hudson, Nicholas Northcote and Swen Smit. 2020. The great acceleration. McKinsey \& Company. Accessed on July 15, 2020, https://www.mckinsey.com/business-funct ions/strategy-and-corporate-finance/our-insights/the-great-acceleration?cid=other-eml-alt-mipmc k\&hlkid=33f92356dad34cd3a14c8e964310e224\&hctky=1543015\&hdpid=d9cf6b8a-1d54-4d038b7b-be32198560be. 
Foster, John Bellamy, and Robert W. McChesney. 2014. Surveillance capitalism: Monopoly-finance: Monopoly-finance capital, the military-industrial complex, and the digital age. Monthly Review 66 (3): $1-33$.

Nathan, Dev. 2020. Oligopoly, knowledge and labour in GVCs. Global Labor Journal 11 (2): 134-151.

Noronha, Ernesto, and Premila D'Cruz. 2016. Upgrading in India's IT industry. In Labour in GVCs in Asia, ed. Dev Nathan, Meenu Tewari, and Sandip Sarkar. Cambridge: Cambridge University Press.

Steenkamp, Jan-Benedict E.M. 2020. Global brand building and management in the digital age. Journal of International Marketing 28 (1): 13-27.

The Economist. 2020. The great unwinding: COVID-19 and the regionalization of supply chains. The Economist Intelligence Unit, June. Accessed July 27, 2020.

Zuboff, Shoshana. 2019. The age of surveillance capitalism: The fight for a human future at the new frontier of power. London: Profile Books.

Publisher's Note Springer Nature remains neutral with regard to jurisdictional claims in published maps and institutional affiliations. 